\title{
LA RELACIÓN ENTRE LOS CONCEPTOS LEIBNIZIANOS DE LIBERTAD Y CREACIÓN Alfredo Gerardo Martínez Ojeda*
}

RESUMEN: La defensa de la libertad humana constituye una de las tareas más problemáticas dentro del sistema de Leibniz. Esto se debe principalmente a que el concepto leibniziano de Dios posee características que resultan aparentemente contradictorias con cualquier tipo de libertad humana. Intentaré mostrar cómo, a fin de disolver las contradicciones que salen al paso, Leibniz recurre a su propio concepto de creación, único punto de vista desde el cual se pueden cumplir los requisitos de la definición leibniziana de libertad. Intentaré, además, mostrar que el mencionado recurso se encuentra presente en la Monadología y que, por tanto, pertenecía a lo que Leibniz consideró una de las versiones más acabadas de su propio sistema.

PALABRAS CLAVE: Leibniz, libertad, creación, predeterminación.
THE RELATIONSHIP BETWEEN THE LIEBNIZIAN IDEAS OF FREEDOM AND CREATION

ABSTRACT: Defending human freedom is one of the most challenging tasks in the Leibnizian system due to the fact that his concept of God has characteristics that are apparently in contradiction with any other notion of human freedom. In this article, I will show how, in order to eliminate those contradictions, Leibniz resorts to his own idea of creation, the only point of view meeting the requirements of his definition of freedom. Furthermore, I will demonstrate how the latter idea is present in the Monadology and thus, it belongs to what Leibniz himself considered one of his most complete version of his own system.

KEYWORDS: Leibniz, freedom, creation, predetermination.

* FFyl UNAm / Departamento Académico de Estudios Generales ITAM. 


\section{LA RELACIÓN ENTRE LOS CONCEPTOS LEIBNIZIANOS DE LIBERTAD Y CREACIÓN}

\section{I}

\section{Alrededor de 1671 Leibniz senten-} ciaba:

De entre todas las preguntas que acucian al género humano, ninguna suscita mayor acaloramiento, es reiterada con tanta frecuencia, ni tampoco acarrea más riesgo o atrocidad, que esta controversia: cómo cabe conciliar la libre voluntad del ser humano, los castigos y las recompensas, con la omnipotencia y la omnisciencia de Dios que lo rige todo. ${ }^{1}$

${ }^{1}$ G. W. Leibniz, "En torno a la omnipotencia y omnisciencia de Dios, y la libertad del hombre", en Escritos en torno a la libertad, el azar y el destino, 1990, Madrid, Tecnos, trad. de Roldán Panadero y Rodríguez Aramayo, p. 57.
El problema de la libertad, esto es, el problema de conciliar la libertad humana con la existencia de un Dios omnipotente y omnisciente, constituyó uno de los temas recurrentes en el pensamiento leibniziano a lo largo de, prácticamente, 30 años. El problema específico de la posible conciliación entre Dios (y sus atributos) y la libertad humana se puede plantear en los siguientes términos: De la suposición de que Dios es omnipotente y omnisciente, se puede concluir que, o bien Dios, en virtud de que lo sabe todo y lo puede todo, lo hace todo y por tanto la libertad humana es imposible; o bien, que Dios lo sabe todo y lo puede todo, pero no lo hace todo y por tanto la libertad humana es posible. En el caso en que Dios lo hace todo, los atributos divinos de la omni- 
potencia y la omnisciencia implican que Dios es la única causa de toda la realidad efectiva de todas las cosas, incluyendo las acciones humanas y cada uno de sus componentes (la elección, por ejemplo). En este supuesto la libertad humana, entendida como la capacidad de ser causa (aunque sea parcial) de mis propias acciones, resulta prácticamente imposible, pues si toda la realidad efectiva de las acciones humanas es atribuible a Dios, el ser humano, en estricto sentido, no actúa sino que el que actúa, siempre, es Dios. De esta forma, parece que lo adecuado, si se quiere conciliar la libertad humana y los atributos divinos de la omnipotencia y la omnisciencia, es suponer que Dios no lo hace todo. Sin embargo, asumir esto implica dar respuesta a la siguiente cuestión: $\mathrm{Si}$ Dios no hace todo, ¿en qué consiste exactamente aquello que Dios no hace y que, sin embargo, existe? Si esto no fuera suficientemente difícil, de plantear e intentar resolver esta cuestión se derivan otras igualmente complejas: ¿Cuál es la razón por la que Dios no hace lo que no hace? ¿Cómo es que existe o en qué sentido se pude decir que existe lo que Dios no hace? ¿Cómo exactamente se relaciona lo que Dios no hace y la libertad humana? A pesar de que optar por esta posición resulta mucho más complicado, es, como dije, la vía que aparece como más adecuada para intentar una explicación que concilie a Dios (y sus atributos) y la libertad humana.

Me parece que, a fin de explicar cómo es que el hecho de que Dios no lo hace todo se relaciona y permite la existencia de la libertad humana, lo más adecuado es enfocar el problema desde la perspectiva de la creación. En efecto, esta es la perspectiva que han adoptado algunos de los autores que han trabajado en una propuesta más o menos conciliatoria de la libertad y los atributos divinos, Leibniz entre ellos. Desde la perspectiva de la creación se puede establecer en qué consiste el creador, en qué consiste la criatura y en qué consiste su relación. Es decir, desde la perspectiva de la creación es posible establecer en qué consiste la diferencia entre creador y criatura, diferencia que permite establecer también qué actos corresponden al creador y cuáles a la criatura y si en estos últimos hay la posibilidad de la libertad. Es esta misma diferencia o distancia entre el creador y la criatura lo que aparece como débil o inexistente si se considera que Dios hace todo: Si en todo acto existente el que actúa es Dios, el agente humano es inexistente, no solo en tanto que agente, sino, incluso, en tanto que individuo. La diferencia entre creador y criatura, los límites de Dios con respecto al ser humano, se tornan inciertos hasta desaparecer: la criatura es anulada por Dios, o, mejor dicho, en Dios. 
II

Expondré, de forma breve y general, la concepción leibniziana de creación, a fin de establecer, desde esta perspectiva, la diferencia entre creador y criatura. La creación, de acuerdo con los principios leibnizianos, consiste en un traslado de las esencias o posibles de la mente divina a la existencia actual. El mundo de las esencias o posibles está completamente realizado en la mente divina, es decir, los posibles son reales (no abstractos) y están completos pero son, sin embargo, incapaces de desarrollar la característica de la existencia, la cual es añadida por Dios a partir de una elección. Si la existencia de la criatura es añadida por Dios y la esencia es construida también por Él, parece que no es posible establecer una diferencia o distancia entre creador y criatura y que, por tanto, la libertad no es posible. La solución leibniziana, me parece, es genial: la existencia de las criaturas sí es añadida por Dios (no podría ser de otra manera); sin embargo, Él no es responsable del diseño de las esencias, sino que se limita a considerarlas tal cual originalmente son. En el parágrafo 46 de Monadología, Leibniz indica cómo las esencias eternas de las cosas son, en este sentido, independientes de la voluntad divina:

Sin embargo, en ningún caso cabe imaginar, como algunos, que las ver- dades, al depender de Dios, son arbitrarias y dependen de su voluntad, tal como parece que Descartes y luego Poiret han supuesto. ${ }^{2}$

Las esencias, los posibles, dependen de Dios en la medida en que la mente divina constituye la región en la que se ubican; sin embargo, los posibles son independientes de Dios en cuanto a su constitución, la cual responde al principio de no contradicción. En esta característica, que llamaré independencia de los posibles en la mente de Dios, consiste el fundamento de la diferencia entre creador y criatura, pues esta implica que al menos un aspecto de la criatura no ha sido completamente causado por Dios, abriéndose así la posibilidad de la libertad humana.

\section{III}

Explicaré a continuación la forma en la que considero que se relaciona la independencia del posible en la mente de Dios con la solución al problema de la libertad. Dado que la independencia del posible en la mente de Dios está, como acabamos de ver, intrínsecamente ligada al problema de la creación, podemos encontrar ya algunas líneas que apuntan hacia ella

${ }^{2}$ Monadología, 2010, Granada, Comares, trad. de Soto-Bruna, $§ 46$, p. 334. 
en el opúsculo conocido como Todo posible exige existir (ca. 1677), en donde Leibniz ofrece por primera vez una formulación explícita y completa del problema. Sin embargo, es en Discurso de metafísica (1686) donde podemos encontrarlo ya como un concepto funcional. En el parágrafo 30 se tratan, entre otros temas, las consecuencias que podría tener la acción de Dios sobre la voluntad humana, en el sentido de que si la voluntad divina determina absolutamente a la humana, aquella tendría que ser considerada como la causa del mal y, por tanto, la voluntad humana resultaría eximida de cualquier responsabilidad y habría que decir que, de alguna forma, Dios es malo. Frente a esta posibilidad, Leibniz establece una separación de las funciones que corresponden por un lado a Dios y por el otro a la criatura, a su noción completa, específicamente, en la producción de la acción humana:

Dios, cuando concurre a nuestras acciones, ordinariamente no hace más que seguir las leyes que Él ha establecido, es decir, conserva y produce continuamente nuestro ser, de modo que los pensamientos nos llegan espontánea o libremente en el orden en los tiene la noción de nuestra sustancia individual, en la cual se los podía prever desde toda la eternidad. ${ }^{3}$

\footnotetext{
${ }^{3}$ Desde este momento (1686), Leibniz fija su postura con respecto al problema de la oposición entre la omnisciencia divina y la libertad humana:
}

Podemos ver cómo esta asignación de funciones, que es al mismo tiempo limitación ${ }^{4}$ de funciones, está basada en el concepto de espontaneidad, es decir, en la idea de que un ser actúa espontáneamente en la medida en que el principio de sus acciones no es externo y excluye, por tanto, toda coacción. De esta forma, a Dios le compete conservary producir nuestro ser; sin embargo, no le compete determinar la sucesión de las acciones (pensamientos en este caso), sino que esto le compete a la noción completa en la que dicha sucesión está ya determinada y desde la cual fluyen espontáneamente las acciones. Acep-

si Dios sabe lo que voy a pensar, entonces no soy libre. Si soy libre, entonces Dios ignora, al menos, una parte de la realidad. Como podrá notarse, la solución leibniziana es peculiar pues no implica elegir uno de los extremos de la disyunción (como hiciera, por ejemplo, Cicerón, al preferir un Dios ignorante), sino que intenta una síntesis: Dios sabe lo que pensaré y lo que haré y, sin embargo, yo soy libre. Esta postura requiere, como he tratado de mostrar, que una "parte" de la criatura no sea configurada por la voluntad divina aunque, por supuesto, dependa de ella en cuanto a su existencia. En esto consiste, precisamente, la independencia de los posibles en la mente de Dios. Es importante señalar, también, que el concepto leibniziano de libertad, por esta misma razón, posee tintes deterministas.

G. W. Leibniz, Discurso de metafísica, $\S 30$, 2010, Granada, Comares, trad. de Ángel Luis González, p. 194.

${ }^{4}$ ¿Hay limitaciones en Dios? El concepto de omnipotencia está, para Leibniz, contextualizado por su concepción intelectualista de Dios. Dios puede todo, pero solo hace lo que debe pues es perfectamente sabio y bueno. De esta forma, las limitaciones no constituyen imperfecciones en Dios sino ausencias coherentes con su propia naturaleza. 
tada esta asignación de funciones, se puede volver sobre el espinoso asunto de la causalidad del mal y contestar que no proviene de la acción de Dios, sino de la criatura, específicamente de la constitución de su noción completa, es decir, existo gracias a Dios y peco gracias a mí, a mi noción completa. Es verdad que en este punto podría considerarse el problema satisfactoriamente resuelto; sin embargo, se impone ahora la necesidad de explicar cómo es que se configura la noción de nuestra sustancia individual, pues si resultara que Dios es, de modo absoluto, el responsable por el diseño de dicha configuración, se seguiría también que nuestra asignación de funciones es una ilusión, dado que ambas tareas (la conservación de mi ser y la determinación de la sucesión de mis acciones) le corresponderían en realidad a Dios, y nos veríamos obligados una vez más a considerarlo la causa única y absoluta del mal. Leibniz se da cuenta de que para poder eximir a Dios de la responsabilidad absoluta en cuanto al diseño del posible es necesario considerar que en la criatura hay condiciones originales que, precisamente debido a su originalidad, explican el diseño. ¿Qué tan originales son estas condiciones? Al menos previas a la creación. Vale la pena aclarar que se usa el término "previas" para indicar una anterioridad causal o de orden y no, obviamente, una anterioridad tem- poral. Las versiones más acabadas de esta idea pueden ser encontradas en la Teodicea y, como indicaré un poco más adelante, en la Monadología. Sin embargo, ya en 1695 (en Conversación con Dobrzensky) está presente y clara la indicación de las condiciones originales de la criatura y de cómo estas condiciones originales limitan la acción de la voluntad divina sin que, por ello, se pueda hablar de imperfección o incapacidad en Dios:

—Pero, ¿de dónde proviene esta imperfección originaria que es anterior al pecado original?

- Cabe decir que proviene de las esencias o naturaleza propia de las creaturas; ya que las esencias de las cosas tienen un carácter eterno, aunque las cosas no lo sean. Siempre ha sido verdad que tres por tres son nueve. Estas no dependen de la voluntad de Dios, sino de su entendimiento; por ejemplo, las esencias o propiedades de los números son eternas e inmutables, y nueve es un número cuadrado no porque Dios lo haya querido, sino porque lo implica su definición, al ser el resultado de multiplicar tres por tres, o sea, un número por sí mismo. El entendimiento de Dios constituye la fuente de las esencias de las creaturas, tal como están en él, esto es, delimitadas. El que sean imperfectas no se debe sino a sus limitaciones, es decir, a que participan de la nada. ${ }^{5}$

5 "Diálogo verídico en torno a la libertad del hombre y el origen del mal (Conversación con 
Los posibles, la noción completa de cada uno de ellos, no son construidos a partir de un designio. No son producto de la voluntad divina, sino que dependen del entendimiento divino cuyo papel se concreta en, permítaseme la expresión, contemplar la configuración de los posibles que dependen de esta contemplación para ser reales, pero no para ser configurados de una u otra forma. ${ }^{6}$

Un poco más tarde (1710) en el parágrafo 104 de La causa de Dios defendida a través de su justicia, conciliada con todas sus otras perfecciones, y con la totalidad de las acciones podemos encontrar ya plenamente

Dobrzensky)", en Escritos en torno a la libertad, el azar y el destino, p. 217.

${ }^{6}$ Se presenta un problema que, por otro lado, tiene su referencia más remota en la Edad Media y que tiene que ver con la distinción entre voluntad antecedente y voluntad consecuente. A pesar de que no pueda atribuirse a Dios la responsabilidad por el diseño de los posibles, parece innegable que si estos contienen acciones malvadas, Dios tiene cierta participación en el mal, pues aunque no los configure, sí los elige y es debido a esa elección que existen. El problema se puede sintetizar así: si Dios conoce las acciones malvadas posibles y las elige, entonces es causa del mal; si no es causa del mal, entonces desconoce las acciones malvadas posibles. Una vez más, Leibniz intenta mantenerse en medio de los dos extremos presentados. Dios conoce las acciones malvadas posibles, pero no las elige en el sentido de que no las quiere (voluntad antecedente), sino que únicamente las elige en el sentido de que las permite (voluntad consecuente), pues de otra forma el resultado final de la elección sería menos perfecto. El mejor de los mundos posibles no es aquel en el que el mal no existe, sino aquel en el que los humanos son libres y ello requiere la posibilidad real de la maldad. desarrolladas las consecuencias de la aplicación de la idea de condiciones originales:

La presciencia o la preordenación de Dios tampoco impone la necesidad, aunque ella misma sea también infalible. Ciertamente Dios vio las cosas en la serie ideal de los posibles como ellas habrían de ser, y en ellas vio al hombre que pecaba libremente; $y$, al decretar la existencia de esta serie, no cambió la naturaleza de la cosa, ni convirtió en necesario lo que era contingente. ${ }^{7}$

¿Por qué Dios no cambió la naturaleza de la cosa a fin de que, en este caso, el pecado no fuera cometido? Porque Dios no puede hacerlo. Dios (hipotéticamente hablando) podría haber elegido otro posible, otro mundo posible en el que el pecado no se cometiera y se evitaran así sus consecuencias, pero no podría haber modificado al posible pecador a fin de que dejara de serlo. La constitución del posible, su esencia, su diseño, su noción completa, está fuera del alcance de la acción de la voluntad divina. El posible no llega, no alcanza la región de los posibles, no se configura como resultado de una volición divina, sino que el posible es

${ }^{7}$ La causa de Dios defendida a través de su justicia, conciliada con todas sus otras perfecciones, y con la totalidad de las acciones, 2012, Granada, Comares, trad. de Tomás Guillén Vera, $\S 104$, p.491. 
pensable o puede ser considerado por el intelecto divino en la medida en que no implica contradicción. El posible, por supuesto, necesita a Dios para ser real, pero no para ser ese posible. La realidad del posible depende del entendimiento divino pero su esencia es independiente, y es a partir de esta independencia que se puede hablar cabalmente de libertad, pues la definición de esta supone la espontaneidad, que a su vez requiere la independencia del posible en la mente de Dios. Para explicar esta relación recurriré a Definición de libertad (1692), en donde Leibniz presenta una exposición sintética de su postura acerca del problema. La obra, si bien es un poco anterior a la posición definitiva contenida en la Teodicea, ofrece la ventaja de presentarse como un sistema de definiciones y corolarios interrelacionados e interdependientes. Ahí se lee:

La libertad constituye una espontaneidad ligada a la inteligencia [...] La espontaneidad representa una contingencia sin coacción, o bien se llama espontáneo a lo que no es necesario ni constreñido [...] Constreñido es aquello cuyo principio proviene de fuera. ${ }^{8}$

8"Definición de la libertad", en Escritos en torno a la libertad, el azar y el destino, p. 207.
El primer requisito (a la par de la contingencia) que Leibniz pone a la libertad consiste en que la acción humana (ámbito al que corresponde la libertad) provenga de un principio interno, pues únicamente de esta forma se puede cumplir con la ausencia de coacción o constricción que constituye la espontaneidad. Claramente, el principio de las acciones humanas es la noción completa de nuestra sustancia individual; sin embargo, ¿se puede sostener que la noción completa constituye realmente un principio interno? Me parece que la respuesta es sí. La noción completa de nuestra sustancia individual es realmente un principio interno de acción gracias a la independencia del posible en la mente de Dios, es decir, gracias al hecho de que Dios no participa en su diseño, sino únicamente en su consideración o contemplación, en su elección como parte del mejor de los mundos posibles y, de forma "posterior" a la creación, en su continua conservación. Así, pienso que se puede sostener que la independencia del posible en la mente de Dios es el fundamento de la espontaneidad, desde la cual, ligada con la inteligencia, surge la libertad. 
IV

Por último, me dirigiré brevemente a la Monadología, y para hacerlo, regresaré primero a la cuestión inicial de este trabajo. Cuando planteé el problema de la libertad en términos de si Dios lo hace todo o no, encontré que la opción coherente con la libertad consistía en suponer que no lo hace todo, pero que esta opción implica determinar la distancia que debe existir entre Dios y sus criaturas o, para decirlo claramente, establecer en qué punto termina Dios y comienza la criatura, en dónde radica la diferencia entre uno y otro, diferencia sin la cual es imposible la existencia de la libertad. Sabemos que la Monadología es una obra de madurez y que Leibniz la consideraba una de las versiones más acabadas y sintéticas de su propio sistema. En este sentido resulta muy interesante que en el parágrafo 42 haga Leibniz alusión precisamente a la distinción de la que se ha venido hablando:

Se sigue también que las criaturas obtienen sus perfecciones del influjo de Dios, y las imperfecciones, en cambio, de su propia naturaleza, incapaz de ser sin límites. En esto, precisamente, se distinguen de Dios. ${ }^{9}$

La posibilidad de distinguir entre las acciones de Dios y las de las criaturas radica, en último término, en su diferencia fundamental u original. A partir de esta distinción es posible asignar una causalidad y, por tanto, una responsabilidad sobre las acciones; es decir, es posible hablar de la libertad humana. La distancia o diferencia entre Dios y sus criaturas, la cual, como he tratado de probar, consiste en la independencia del posible en la mente de Dios, constituye, pienso, el hilo de Ariadna capaz de hacernos salir sanos y salvos del laberinto de la libertad. 
CITAM Derechos Reservados.

La reproducción total o parcial de este artículo se podrá hacer si el ITAM otorga la autorización previamente por escrito. 